ORIGINAL ARTICLE

\title{
Disruption of a novel member of a sodium/hydrogen exchanger family and DOCK3 is associated with an attention deficit hyperactivity disorder-like phenotype
}

\author{
M G de Silva, K Elliott, H-H Dahl, E Fitzpatrick, S Wilcox, M Delatycki, R Williamson, D Efron, \\ $M$ Lynch, S Forrest
}

J Med Genet 2003;40:733-740

See end of article for authors' affiliations ......................

Correspondence to: Dr M de Silva, The Murdoch Childrens Research Institute, 10th Floor, Royal Children's Hospital, Flemington Road, Parkville, Victoria 3052, Australia; desilvmi@ cryptic.rch.unimelb.edu.au

Revised version received 19 May 2003

Accepted for publication 19 May 2003

\begin{abstract}
Background: Attention deficit hyperactivity disorder (ADHD) is a complex condition with high heritability. However, both biochemical investigations and association and linkage studies have failed to define fully the underlying genetic factors associated with ADHD. We have identified a family co-segregating an early onset behavioural/developmental condition, with features of ADHD and intellectual disability, with a pericentric inversion of chromosome 3, 46N inv(3)(p14:q21).

Methods: We hypothesised that the inversion breakpoints affect a gene or genes that cause the observed phenotype. Large genomic clones (P1 derived/yeast/bacterial artificial chromosomes) were assembled into contigs across the two inversion breakpoints using molecular and bioinformatic technologies. Restriction fragments crossing the junctions were identified by Southern analysis and these fragments were amplified using inverse PCR.

Results: The amplification products were subsequently sequenced to reveal that the breakpoints lay within an intron of the dedicator of cytokinesis 3 (DOCK3) gene at the p arm breakpoint, and an intron of a novel member of the solute carrier family 9 (sodium/hydrogen exchanger) isoform 9 (SLC9A9) at the q arm. Both genes are expressed in the brain, but neither of the genes has previously been implicated in developmental or behavioural disorders.

Conclusion: These two disrupted genes are candidates for involvement in the pathway leading to the neuropsychological condition in this family.
\end{abstract}

G enetic association and linkage studies have failed to contribute significantly to the understanding of the genetic basis of neuropsychiatric disorders. Although some positive results have been reported, these are often closely followed by reports that refute the finding. This has also been the case for one of the most commonly diagnosed disorders in children, attention deficit hyperactivity disorder (ADHD)

ADHD is currently defined using DSM-IV criteria (Diagnostic and Statistical Manual IV), and different clinical presentations can be seen. Individuals with ADHD have symptoms that come under the broad heading of either inattentiveness or hyperactivity, but they can also present with signs of both. Diagnosing ADHD is complicated, as other conditions can result in similar behaviours. Such conditions may require different interventions, but we lack the biochemical or genetic diagnostic markers with which to discriminate between them. It is therefore important to understand the aetiology of ADHD and similar conditions to develop better molecular diagnostic criteria and treatment strategies. Studies have indicated that ADHD has a high heritability factor and therefore there is clearly a genetic basis. ${ }^{12}$ Defining a gene involved in the development and progression of ADHD may lead to studies examining differential response to treatments depending on patients' mutational status.

We have identified a family where a young boy presented with features of ADHD and intellectual disability. ${ }^{3}$ Karyotype analysis revealed that he carried one normal and one abnormal copy of chromosome 3. The abnormality was a pericentric inversion, $46 \mathrm{~N}$ inv(3)(pl4:q21). Cytogenetic analysis of 21 members of the proband's family revealed that ten other members carried the inversion. It was reported by a family member that all individuals carrying the chromosome inversion also exhibited a similar phenotype to that of the proband.

To determine whether the behavioural-developmental phenotype co-segregated with the chromosome inversion, the IQ scores of four children and four adults with the inversion were compared with the IQ scores of five children and two adults with normal karyotypes. Overall, the mean IQ of eight individuals with the inversion was 76.6, compared with 93.7 for the seven individuals without the inversion $(p=0.03)$. Furthermore, the four children who carried the pericentric inversion of chromosome 3 were found to have more significant developmental disabilities than the four children without the inversion who underwent neuropsychological assessment. ${ }^{3}$ The clinical phenotypic features in common were intellectual difficulties and an impulsive behaviour style manifesting from early childhood. Three of the four control children had less severe developmentalbehavioural problems with later onset. Specifically, two had learning difficulties and one had reactive emotional disturbance. Clinical assessment clearly differentiated family members with the inversion as having a shared phenotype

Abbreviations: ADHD, attention deficit hyperactivity disorder; $B A C$, bacterial artificial chromosome; FITC, fluorescein isothiocyanate; FISH, fluorescence in situ hybridisation; PAC, P1-derived artificial chromosome; PCR, polymerase chain reaction; STS, sequence tagged site; YAC, yeast artificial chromosome 
with impulsive behaviour and intellectual deficit the key defining elements.

We hypothesised that the inversion in the proband is causally linked to the behavioural phenotype. By studying the genes affected by the chromosome breaks we hoped to identify at least one gene involved in the development of this specific developmental-behavioural phenotype. This paper describes the process utilised to define the breakpoints and the discovery and characterisation of two genes, DOCK 3 and SLC9A9 (GenBank acession nos AY254099 and AY254100 respectively), interrupted by the inversion. Both genes are expressed in the brain but have not previously been associated with psychiatric conditions.

\section{METHODS}

\section{Cell lines and culture conditions}

Cell lines established from proband and control lymphoblasts were grown in RPMI 1640 (Trace Scientific Ltd., Melbourne, Australia) supplemented with $10 \%$ foetal bovine serum (Trace Scientific Ltd.) and $0.8 \mathrm{mmol} / \mathrm{l}$ glutamine at $37^{\circ} \mathrm{C}$, in a humidified chamber in an atmosphere of $5 \% \mathrm{CO}_{2}$ in air. Fibroblast cell lines from the proband and control individuals were grown under similar conditions in DMEM (Trace Scientific Ltd.). All cells were mycoplasma-free.

\section{Cytogenetic analysis}

Chromosome preparations were prepared using standard procedures ${ }^{4}$, and $\mathrm{G}$ banded chromosomes were assembled and described according to the International System of Human Cytogenetic Nomenclature recommendations. ${ }^{5}$

\section{Fluorescence in situ hybridisation analysis}

Fluorescence in situ hybridisation (FISH) was performed as previously described. ${ }^{6}$ The hybridisation mixture contained 6-12 $\mu \mathrm{g}$ of whole yeast DNA or 50-100 ng of Pl-derived artificial chromosome (PAC) or bacterial artificial chromosome (BAC) DNA labelled with biotin-16 dUTP using a nick translation kit (Roche Diagnostics GmbH, Mannheim, Germany), $10 \mu \mathrm{g}$ human cot-1 DNA (Roche) and $2.5 \mu \mathrm{g}$ salmon sperm DNA (Roche) in 50\% formamide, $10 \%$ dextran sulphate and $2 \times$ SSC. To perform two colour FISH with a marker probe, $6-12 \mu \mathrm{g}$ of whole yeast DNA containing the yeast artificial chromosome (YAC) clone $968 \mathrm{~d} l$ labelled with digoxigenin was added to the hybridisation mix.

Signal detection was achieved using fluorescein isothiocyanate (FITC) conjugated to avidin (diluted $1 / 100$, Vector Laboratories, Burlingame, CA) followed by alternate incubations with biotinylated goat anti-avidin (diluted 1/250, Vector Laboratories) and FITC-avidin. The digoxigenin signal was amplified and detected with anti-digoxigenin monoclonal antibody (mouse; Sigma Chemical Company, St. Louis, MO, USA), TRITC labelled anti-mouse IgG (rabbit, Jackson Immunoresearch Laboratories Inc., West Grove, PA, USA) and TRITC labelled anti-rabbit IgG (donkey; Jackson Immunoresearch Laboratories Inc.). Metaphase chromosomes were counterstained with 4', 6'-diamidino-2-phenylindole (DAPI, Sigma Chemical Company; $0.5 \mu \mathrm{g} / \mathrm{ml}$ in Vectashield, Vector Laboratories) and viewed using a Zeiss Axioskop microscope (Carl Zeiss, Oberkochen, Germany) with a CCD camera (Photometrics, Tuscon, AZ, USA) and V for Windows software (Digital Optics, Auckland, New Zealand). A minimum of 20 metaphases per slide was viewed and FISH with each probe was performed at least in triplicate.

\section{Sequence tagged site marker mapping}

Sequence tagged site (STS) markers were mapped to YAC and PAC clones using the polymerase chain reaction (PCR). Primer sequences were obtained at http://www-genome.wi. mit.edu/. Whole YAC, PAC or BAC DNA was used as template, and PCR was carried out on a PCR Express thermal cycler (Hybaid Limited, Ashford, Middlesex, UK).

\section{Southern blot analysis}

Following genomic DNA fragment separation on a $0.8 \%$ agarose gel, the DNA was transferred to Hybond- $\mathrm{N}^{+}$membrane (Amersham Life Science, Amersham, Bucks, UK) by capillary transfer in $0.4 \mathrm{~mol} / \mathrm{l} \mathrm{NaOH}$. A $50 \mathrm{ng}$ sample of probe DNA was ${ }^{32} \mathrm{P}$ labelled with $30 \mu \mathrm{Ci}\left[\alpha^{-32} \mathrm{P}\right] \mathrm{dATP}(3000 \mathrm{Ci} /$ mmol; NEN Life Science, Boston, MA, USA) in a standard random primed reaction. ${ }^{7}$ Hybridisation at $65^{\circ} \mathrm{C}$ extended for up to 18 hours. Membranes were washed at room temperature in $2 \times \mathrm{SSC} / 0.1 \% \mathrm{SDS}$ for $5 \mathrm{~min}$, then in $0.1 \times \mathrm{SSC} / 0.1 \%$ SDS at $65^{\circ} \mathrm{C}$ for $10 \mathrm{~min}$. This wash was then repeated for $20 \mathrm{~min}$ and the filters were exposed to BioMax MS autoradiography film (Eastman Kodak Company, Rochester, NY, USA) with an intensifier screen at $-70^{\circ} \mathrm{C}$ for up to 7 days.

\section{Phage library construction from YAC DNA}

Proteinase $\mathrm{K}$ was used to prepare high molecular weight yeast DNA from Saccharomyces cerevisiae cells containing y814hl0, which were embedded in agarose. ${ }^{8}$ Total yeast DNA was partially digested using the restriction enzyme Sau3AI (Roche) and was size fractionated by separating the fragments under pulsed field gel electrophoresis (Gene Navigator System, Pharmacia Biotech AB, Uppsala, Sweden) and excising fragments of between 9 and $20 \mathrm{~kb}$ in size from the gel. Agarase enzyme (Roche) was used to digest the agarose away from the DNA fragments, which were then ligated into the lambda ZAP Express vector predigested with BamHI and treated with calf intestinal alkaline phosphatase according to the manufacturer's directions (Stratagene, La Jolla, CA, USA).

\section{Phage library analysis}

The library was plated onto XL1-Blue MRF' Escherichia coli host cells. Plaques were lifted onto to Hybond- $\mathrm{N}^{+}$membrane. Clones in the breakpoint region were identified by hybridisation of STS markers in the critical area by the method outlined above for analysis of Southern blots.

\section{Inverse PCR amplification of unknown genomic sequences}

Genomic DNA isolated from lymphoblast cell lines established from the proband and control individuals was completely digested with the HindIII restriction endonuclease (Roche). Fragment ends were self ligated using 10 U T4 DNA ligase (Roche) for every $\mu \mathrm{g}$ DNA. Circularisation of the fragments was encouraged by dilute ligation reaction conditions. Inverse PCR oligomers were designed to $3 p$ sequences located just within the inverted portion of the chromosome. Amplimers 0299-li (GTCAATGAGGGCTGTCAATGG) and 0299-2i (CAAGGAAGACCAAGCAACCAAC) amplified the unknown 3q DNA adjacent to the known 3p sequences using the Expand Long Range PCR kit System 3 (Roche) according to the manufacturer's directions. The PCR cycle consisted of a single incubation at $94^{\circ} \mathrm{C}$ for $2 \mathrm{~min}$, followed by 10 cycles of $94^{\circ} \mathrm{C}$ for $10 \mathrm{~s}, 52^{\circ} \mathrm{C}$ for $30 \mathrm{~s}, 68^{\circ} \mathrm{C}$ for $12 \mathrm{~min}$, then 20 cycles of $94^{\circ} \mathrm{C}$ for $10 \mathrm{~s}, 52^{\circ} \mathrm{C}$ for $30 \mathrm{~s}, 68^{\circ} \mathrm{C}$ for $12 \mathrm{~min}$ (increasing by $20 \mathrm{~s}$ each cycle), then a single extension step of $68^{\circ} \mathrm{C}$ for 7 min.

\section{PCR amplification of breakpoint sequences}

Primers 0299-11i (GCTTTAGCAGGCTGACATCAAC) and NHE-6 (GAGTTGCCAGCCAGTCTTTA) were used to amplify a $761 \mathrm{bp}$ fragment across the $3 \mathrm{p}$ breakpoint. A $262 \mathrm{bp}$ fragment was amplified across the $3 q$ breakpoint using the oligomers 0299-7i (CTGTTCCTGACTTGGAAACAC) and 02998 i (CCTGCAAGTACATGTTCTAG). The PCR cycle for both 
A

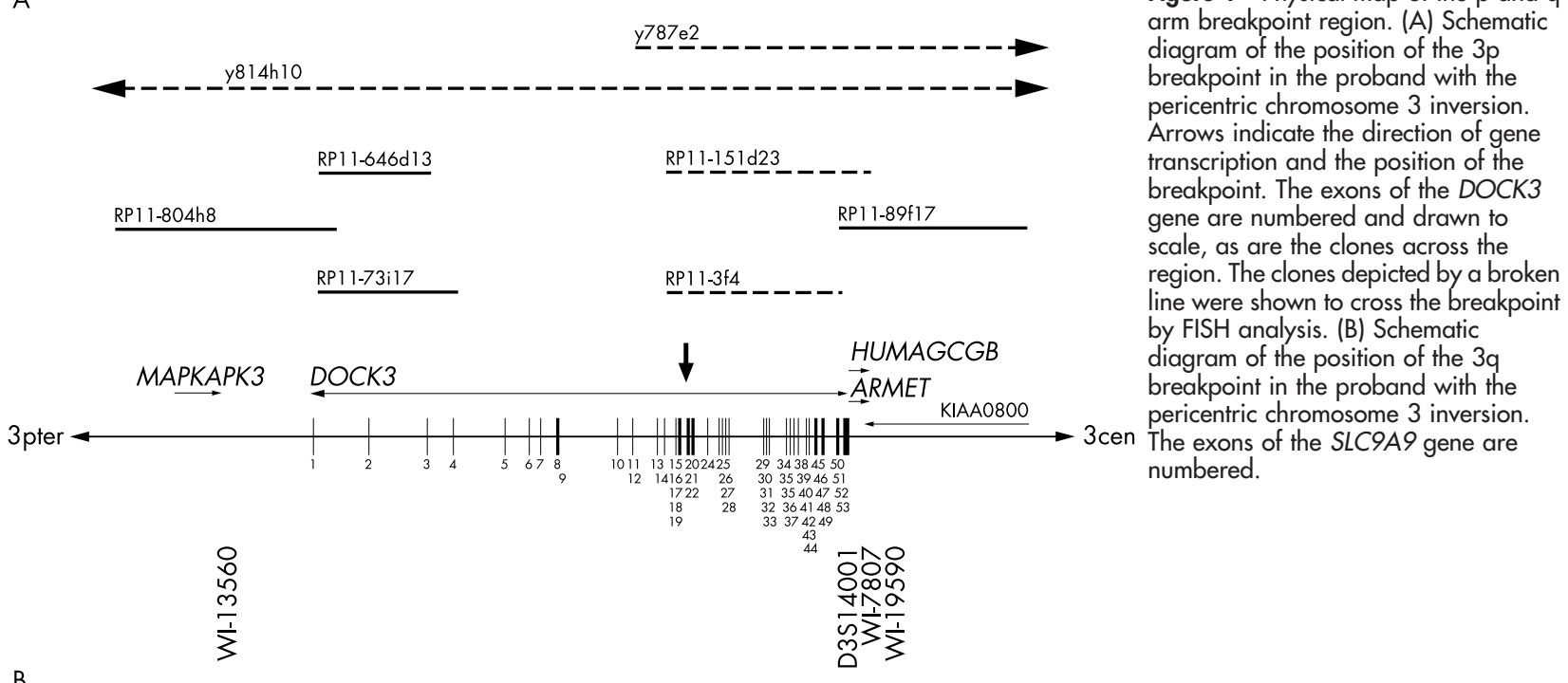

B

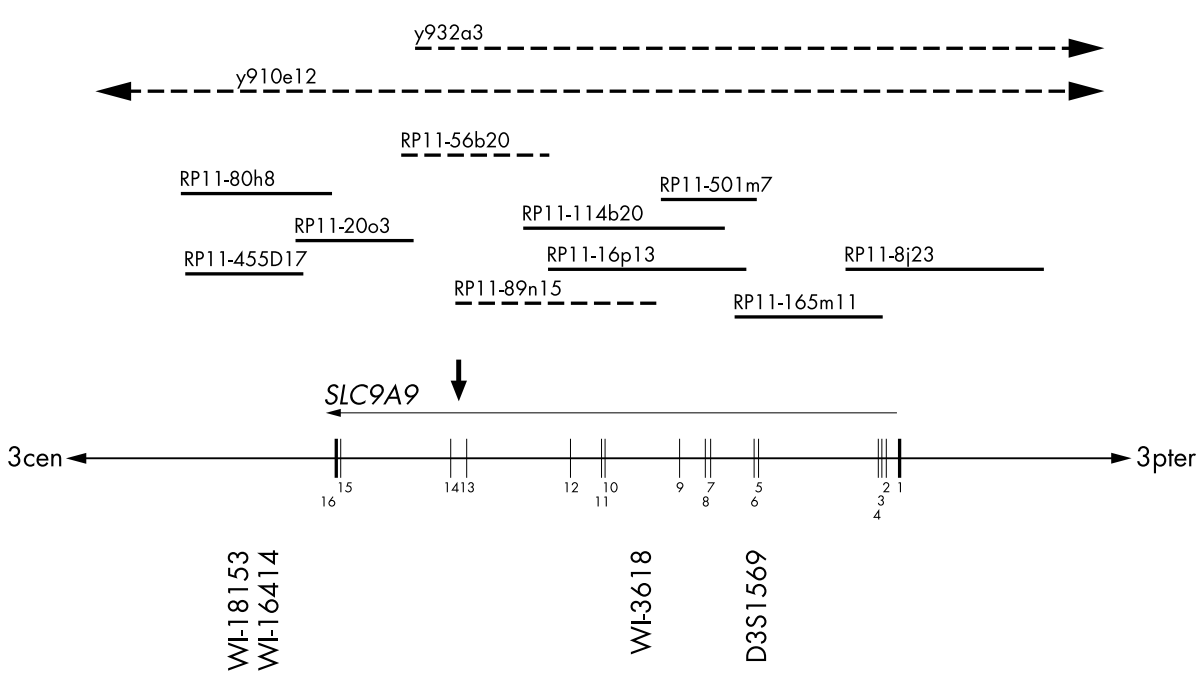

primer pairs consisted of a single incubation at $94^{\circ} \mathrm{C}$ for $1 \mathrm{~min}$, followed by 35 cycles of $94^{\circ} \mathrm{C}$ for $30 \mathrm{~s}, 55^{\circ} \mathrm{C}$ for $30 \mathrm{~s}$ and $72^{\circ} \mathrm{C}$ for 1 min with a final single extension step of $72^{\circ} \mathrm{C}$ for $5 \mathrm{~min}$. The resulting PCR products were processed by direct sequencing analysis.

\section{5' RACE}

To isolate the 5' cDNA ends of candidate genes, nested gene specific primers were designed from internal exons of the two genes. These primers were used to carry out RACE using the SMART-RACE system (Clontech Laboratories Inc., Palo Alto, CA, USA) and RACE ready cDNA from human foetal brain (Clontech Laboratories Inc.). The resulting PCR products were processed by direct sequencing analysis.

\section{Sequence analysis}

Fluorescent DNA sequencing using custom primers and BigDye terminator chemistry (Applied Biosystems) was carried out. Gel separations were conducted at the Australian Genome Research Facility (Melbourne, Australia).

\section{RNA analysis}

Premade multiple tissue Northern blots were probed with cDNA sequences from the DOCK3 and SLC9A9 genes following manufacturer's recommendations (Clontech Laboratories
Inc.). The DOCK3 probe, IMAGE clone 3578322 (GenBank accession no. BF593175), corresponded to nucleotides 65308432 of the mRNA sequence and the SLC9A9 probe, an RTPCR amplicon using primers NHE-4 (GCATGAAACTGG AGGAGCAATGG) and NHE-5 (CTGGCCAGCATGTATCAT AGCC) encompassed nucleotides 147-579 of the mRNA sequence. For both genes, base pair numbering began at the ATG translation start site.

\section{Mouse RNA in situ hybridisation}

Whole mouse embryos collected at 12.5 d.p.c or adult mouse heads were fixed at $4{ }^{\circ} \mathrm{C}$ overnight in $4 \%$ paraformaldehyde in PBS. Tissue was embedded in Tissue-Tek ${ }^{\circledR}$ OCT compound (Sakura Finetek, Torrance, CA, USA) and 10-20 $\mu \mathrm{m}$ thick cryosections were transferred onto superfrost plus glass microscope slides (BDH) and stored frozen. We generated sense and anti-sense RNA probes by transcription of the T3 or T7 RNA polymerase promoter in the presence of digoxigeninUTP (Roche). We detected hybridised probes with an alkaline phosphatase coupled antidigoxigenin antibody (Roche).

\section{Computer analysis}

BLAST analysis of the genomic sequences for construction of $\mathrm{BAC}$ contigs and the identification of transcribed sequences and known genes were carried out using the publicly 
available databases at the NCBI (http://www.ncbi.nlm.nih. gov/). GRAIL analysis for the prediction of potential exons at the UK HGMP site was used with the NIX program (http:// www.hgmp.mrc.au.uk/Registered/Webapp/nix/).

\section{RESULTS}

\section{Identification of the $p$ and $q$ arm breakpoints}

We previously identified a pericentric inversion of chromosome 3 co-segregating with a behavioural-developmental phenotype in an extended pedigree. The affected individuals carried one copy of the inverted chromosome and one normal copy of chromosome 3. By conventional cytogenetics, the region involved in the duplication extended from $3 \mathrm{pl} 4$ to $3 \mathrm{q} 21 .^{3}$

A panel of YAC clones (http://www-genome.wi.mit.edu/) was mapped to the abnormal chromosome 3 using FISH on a lymphoblast cell line established from the proband. Subsequent chromosome walking resulted in the identification of two YAC clones spanning each junction (fig 1A, B). At the q arm breakpoint, clone y932a3 was of unknown size and the other clone y910e12 was $1650 \mathrm{~kb}$. At the $\mathrm{p}$ arm, clone y814h10 was $1640 \mathrm{~kb}$ in size and the other, y787e2, was chimeric and consisted of one species of $420 \mathrm{~kb}$ and one of $660 \mathrm{~kb}$.

To facilitate analysis of the gene content of the critical regions, smaller overlapping $\mathrm{BAC}$ and $\mathrm{PAC}$ clones were identified and mapped by FISH (fig 1A, B). Construction of a high density BAC/PAC contig was hampered by the presence of a high proportion of repetitive sequence elements around both breakpoints. To overcome this obstacle, a $\lambda$ phage library was constructed from one of the YAC clones (y814h10) that spanned the $\mathrm{p}$ arm breakpoint. EST and STS markers in the vicinity of the breakpoint were used as probes to screen this library by hybridisation. Sequence analysis of five clones isolated from screens of the lambda library revealed the presence of four closely mapping genes, ARMET, HUMAGCGB, KIAA0800 (GenBank accession nos XM_039258, XM_002855, and XM_039257, respectively) and DOC $K 3$. The gene sequences were used to screen the high throughput genome sequence database at the National Center for Biotechnology Information (NCBI, Bethesda, MD, USA; http:/www.ncbi.nlm.nih.gov/), and three overlapping human BAC clones containing these genes were found. The BAC clones were analysed by FISH, with one (RP11-89f17) localising within the chromosome inversion, and two clones (RP1l-3f4 (fig 2A) and RP1l-15ld23) crossing the p arm breakpoint. To view figure 2, please visit the website (www.jmedgenet.com).

Based on the signal intensity observed in the FISH experiments using the BAC clone RP1l-3f4 (fig 2A) that spans the breakpoint, we estimated that the breakpoint lay within the telomeric third of this clone. We tested probes from unique segments of the BAC by Southern blot hybridisation against the patient DNA and fixed the breakpoint to within a $4 \mathrm{~kb}$ HindIII fragment of genomic DNA. This placed the $\mathrm{p}$ arm breakpoint within an intron of the DOCK3 gene (fig 2B).

\section{Analysis of the DOCK3 gene}

Sequence comparison to family members DOCK1 and DOCK2 suggested that the entire DOCK3 gene sequence was not available on the public databases. The sequences of the related genes were used to identify putative $5^{\prime}$ DOCK3 gene sequences in a contig of BAC clones located telomeric to BACs RP11-3f4, RP11-15ld23, and RP11-89f17 (fig 1A). A combination of RT-PCR and 5' RACE experiments were used to confirm the predicted $5^{\prime}$ sequence of the gene and demonstrated that the gene is larger than predicted by the publicly available data. By comparing the $8.45 \mathrm{~kb}$ cDNA sequence to the genomic sequence of the critical region it was shown that the DOCK3 gene has 53 exons and spans approximately $465 \mathrm{~kb}$ of genomic DNA (figs 1A, 2C). The inversion breakpoint lies between exons 19 and 20. The predicted protein consists of 2030 amino acids and has a molecular weight of $233.1 \mathrm{kDa}$. Its sequence predicts a soluble protein with an $\mathrm{SH} 3$ domain in the $\mathrm{N}$-terminal region.

Previous data (http://www.kazusa.or.jp/huge/index.html) suggested that the DOCK3 gene is expressed at relatively low levels in brain and testis. By probing multiple tissue Northern blots, we confirmed that the gene is expressed in brain (fig 3A, B). Specifically the gene was expressed in the cerebellum, cerebral cortex, medulla, occipital pole, frontal lobe, temporal lobe, and putamen. There was no expression in the spinal cord or in heart, skeletal muscle, colon, thymus, spleen, kidney, liver, small intestine, placenta, lung, and peripheral blood leukocytes. Expression in the testis, but not in the sperm, was confirmed by RT-PCR (data not shown). Expression could not be detected in lymphoblast or fibroblast cell lines established from samples from the proband and control subjects by Northern blot analysis (data not shown).

A panel of cDNA from varying stages of mouse embryonic development was examined for expression of the DOCK3 gene. Expression was first detected in the $12.5 \mathrm{dpc}$ mouse embryo and was then maintained throughout development (data not shown). In situ hybridisation analysis of $12.5 \mathrm{dpc}$ whole mouse embryos supported the results found in adult human tissues with low level, generalised expression detected in the developing brain (fig 3C).

\section{Identification of the SLC9A9 gene}

The known genomic sequence around the $3 p$ breakpoint was used to design oligomers for inverse PCR experiments to identify the unknown sequences of $\mathrm{q}$ arm origin. Combining inverse PCR with long range PCR, the $4 \mathrm{~kb}$ HindIII breakpoint fragment from the inverted chromosome was amplified. Direct sequencing of the fragment revealed the $\mathrm{q}$ arm sequences fused to the $\mathrm{p}$ arm sequences. BLAST analysis against the high throughput genome database at NCBI revealed the exact position of the $3 q$ breakpoint on the contig we had assembled using both laboratory based chromosome walking and in silico methods (fig 1B).

It was found that the $3 \mathrm{q}$ breakpoint sequence is in the chromosome segment represented by the overlap between BAC clones RP11-89n15 and RP11-56b20. Analysis of these clones by FISH confirmed that RP11-56b20 spanned the $\mathrm{q}$ arm breakpoint (fig 4A). To view figure 4, please visit the website (Www.jmedgenet.com). RP11-89n15 was not previously shown to cross the breakpoint using FISH analysis, as only $4 \mathrm{~kb}$ of clone DNA extended across the junction and of that, $3.6 \mathrm{~kb}$ contained repetitive elements that were suppressed by pre-incubating the probe with human cot-1 DNA. A search of the publicly available databases using the NIX program at the HGMP site uncovered an EST with homology to a sodium/hydrogen ion exchanger family, Homo sapiens solute carrier family 9 (SLC9). This novel gene, termed SLC9A9, was assembled using computer analyses of EST markers along the BAC clones in the critical region and sequence similarity to other SLC9 gene family members.

By comparing the $3.4 \mathrm{~kb}$ cDNA sequence to the genomic sequence, it was shown that the SLC9A9 gene has 16 exons and spans approximately $470 \mathrm{~kb}$ of genomic DNA (fig 1B). The inversion breakpoint lies between exons 13 and 14 (fig 4B, C). The predicted SLC9A9 protein has 645 amino acids and a molecular weight of $72.6 \mathrm{kDa}$. Its sequence suggests a membrane bound protein with 10 transmembrane domains.

Once the sequence around the breakpoints was identified it was possible to design oligomers that amplified the sequence 
A
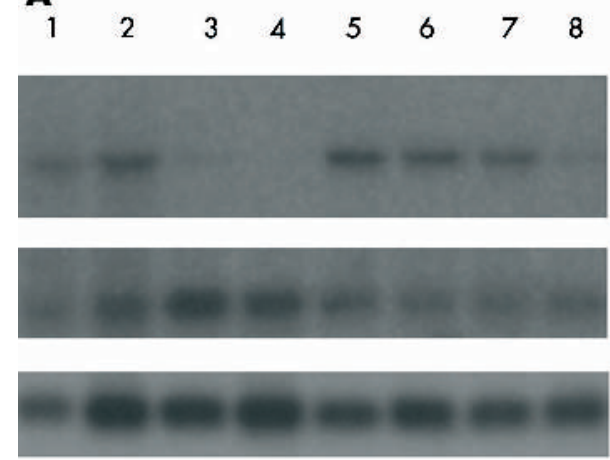

1. Cerebellum

2. Cerebral cortex

3. Medulla

4. Spinal cord

5. Occipital lobe

6. Frontal lobe

7. Temporal lobe

8. Putamen

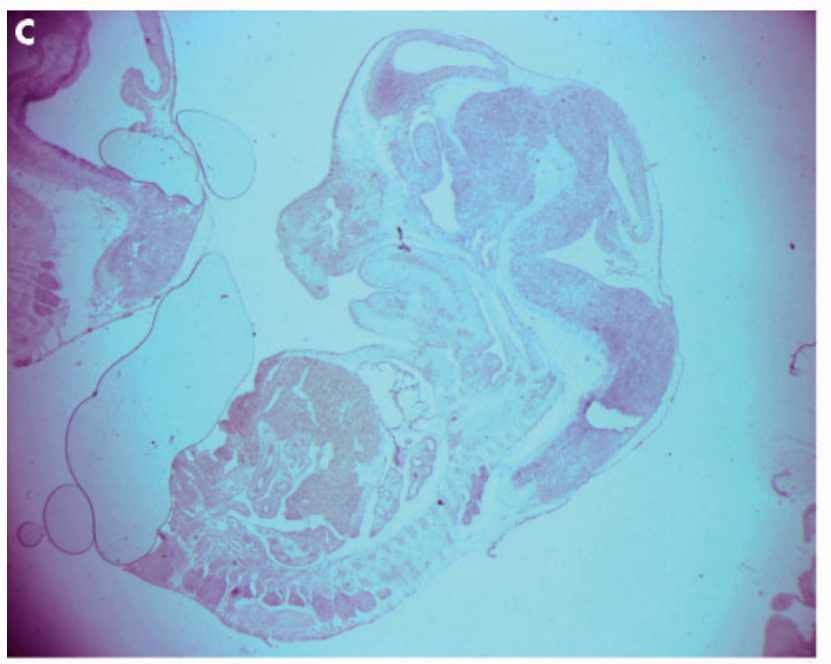

DOCK 3

SLC9A9

Bactin
B

$\begin{array}{llllllllllll}1 & 2 & 3 & 4 & 5 & 6 & 7 & 8 & 9 & 10 & 11 & 12\end{array}$

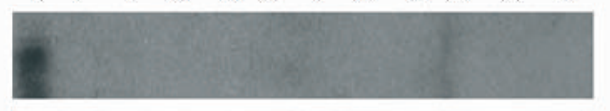

DOCK 3



$7.5 \mathrm{~kb}$

SLC9A9

$3.5 \mathrm{~kb}$

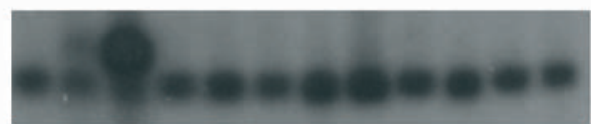

Bactin
1. Brain (whole)
2. Heart
3. Skeletal muscle
4. Colon
5. Thymus
6. Spleen
7. Kidney
8. Liver
9. Small intestine
10. Placenta
11. Lung
12. Peripheral blood
leukocyte



Figure 3 Expression pattern of the DOCK3 and SLC9A9 genes in adult human and mouse embryo tissues. In panel (A), Northern analysis of human adult brain tissues showing an approximately $8.5 \mathrm{~kb}$ DOCK3 message and a message about $3.4 \mathrm{~kb}$ for the SLC9A9 gene. (B) A panel of multiple adult human tissues was probed for expression of the DOCK3 and SLC9A9 genes. (C) In situ hybridisation analysis of 12.5 dpc mouse embryos of the DOCK3 gene. Expression is low level and generalised throughout the brain. (D) A 12.5 dpc mouse embryo analysed for SLC9A9 expression by in situ hybridisation. $\mathrm{H}$, developing heart; $\operatorname{tg}(\mathrm{V})$, trigeminal ganglion; fg (VII), facial nerve ganglion; vcg (VIII), vestibulocochlear ganglion; igv (X), inferior ganglion of the vagus nerve; drg, dorsal root ganglia.

across the junctions on both the $\mathrm{p}$ and $\mathrm{q}$ arm of the inverted chromosome. By comparison with the sequence on the normal chromosome, it was shown that in the inversion process four base pairs were lost at the $\mathrm{p}$ arm breakpoint and one at the q arm (fig 5).

\section{Expression analysis of SLC9A9}

Northern analysis of a panel of human adult tissues demonstrated that the expression of SLC9A9 is fairly widespread (fig 3A, B). Although expressed in the brain, highest expression is seen in heart and skeletal muscle, followed by the placenta, kidney, and liver. In the brain, the highest levels of expression were seen in the medulla and spinal cord. Expression, as detected by Northern analysis, could not be seen in the lymphoblast or fibroblast cell lines from the proband and control subjects (data not shown).

These data were supported by in situ hybridisation analysis of $12.5 \mathrm{dpc}$ whole mouse embryos (fig 3D), showing high levels of expression in the developing heart, somites, and regions of the brain. In particular, strong expression was detected in the ganglia of the trigeminal, facial, vestibulocochlear, and vagus nerves, and in the dorsal root ganglia.

\section{DISCUSSION}

The extensive physical mapping of the inversion breakpoints of a pericentric inversion of one copy of chromosome 3 co-segregating with a behavioural-developmental phenotype with features of ADHD revealed the disruption of a gene at 
each inversion junction. The gene interrupted at the $\mathrm{p}$ arm, $D O C K 3$, is a member of the CDM family of proteins, which also includes CED-5 from Caenorhabditis elegans, myoblast city from Drosophila melanogaster, and human DOCK1 and DOCK2. At the q arm, we discovered a novel member of the Homo sapiens solute carrier family 9 (sodium/hydrogen exchanger), termed SLC9A9. The disruption of these sequences suggests to us that one or both of these genes are strong causal candidates for the observed phenotype in the family under investigation.

Neither of the genes has been implicated in developmental or behavioural pathways previously, and our present knowledge about their functions does not allow us to make conclusions about their contribution and roles in the condition caused by this unique inversion. We therefore examined the expression patterns of the mRNA of the two genes. Previous data (http://www.kazusa.or.jp/huge/ index.html) indicated that the DOCK3 gene was expressed at relatively low levels in only the brain and testis. By probing multiple tissue Northern blots with a probe for the DOCK3 gene, we confirmed that the expression of this gene is essentially restricted to the brain. When compared with the in situ hybridisation results, the gene appears to be expressed at low levels in a generalised fashion throughout the brain. The DOCK3 message is seen at highest levels in the frontal, temporal, and occipital lobes. Interestingly, the brains of individuals with ADHD show hypoactivity and reduced blood flow of the prefrontal regions of the brain', and alterations to the basal ganglion. ${ }^{10} 11$

The CDM protein family has been shown to play an important role in the engulfment of apoptotic cells and in the migration of cells. ${ }^{12-17}$ Expression of the CrkII-p130 Cas complex recruits DOCKI to focal adhesions at the cell membrane. When DOCKI binds the adaptor protein crkII, signals are transduced to the cytoskeleton and the c-Jun Nterminal kinase-stress activated protein kinase (JNK) by means of the activation of Rac, ${ }^{16}{ }^{18}$ one of the Rho family small G-proteins. ${ }^{19}$ DOCK2 also mediates Rac activation, but unlike DOCKI does not bind the CrkII protein at its C terminus.

The expression of DOCK1 and DOCK2 appears to be exclusive, with DOCK2 expression restricted to non-adherent cells from haemapoietic tissues ${ }^{12} 20$ and DOCKI expressed in most other tissues. ${ }^{21}$ DOCK2 is crucial for correct lymphocyte migration into the subcompartments of the lymphoid organs. Fukui et al., ${ }^{12}$ demonstrated that DOCK2 knockout mice had abnormal lymphoid organ architecture caused by the incorrect migration of lymphocytes. With DOCK3 expression restricted to the brain and testis, it is enticing to speculate that this protein performs an important role in cell migration in these tissues. A lack of the DOCK3 protein could disrupt migration of neuronal tissues disrupting brain circuits and causing alterations to behaviour and intellectual development.

It has recently come to light that DOCK3 is analogous to the modifier of cell adhesion protein (MOCA; previously called presenilin binding protein). Work has shown that DOCK3 binds to presenilinl, ${ }^{22}{ }^{23}$ a protein associated with $\gamma$ secretase in $\beta$-amyloid precursor protein, mutations in which have been linked to early onset familial Alzheimer's disease. ${ }^{24}$ This study also hypothesises that aberrant DOCK3 expression may alter cell migration and axon pathfinding.

The sodium/hydrogen exchangers are plasma membrane proteins that mediate the exchange of extracellular $\mathrm{Na}^{+}$for intracellular $\mathrm{H}^{+}$. Prior to this study, eight distinct isoforms (SLC9A1 to SLC9A8) had been isolated. They share $20-70 \%$ amino acid identity (calculated $M_{\mathrm{r}}$ ranging from $\sim 74000$ to 93000 ) and exhibit similar membrane topologies, with 10-12 predicted $\mathrm{N}$-terminal membrane spanning $\alpha$-helices and a large C-terminal cytoplasmic region. The SLC9A family participates in a wide array of essential cellular processes, including control of intracellular $\mathrm{pH}$, maintenance of cellular volume, and reabsorption of sodium across renal, intestinal, and other epithelia. ${ }^{25-29}$ The SLC9A9 protein identified in this study has highest similarity to SLC9A6 and SLC9A7, both of which are located on the membranes of subcellular organelles, mitochondria, and trans-Golgi network respectively. ${ }^{28} 29$

Northern analysis of a panel of human adult tissues demonstrated that the expression of SLC9A9 is fairly widespread. Although expressed in the brain, its highest expression is seen in the heart and skeletal muscle, followed by the placenta, kidney, and liver. In the brain, the highest levels of expression were seen in the medulla and spinal cord. Close inspection of in situ hybridisation images of $12.5 \mathrm{dpc}$ mouse embryos shows a relatively high level of staining to the ganglia of the trigeminal, facial, vestibulocochlear cranial nerves, the inferior ganglion of the vagus, and the dorsal root ganglia, which house the cell bodies of sensory axons entering the spinal cord via the dorsal roots. ${ }^{30}$

Correct functioning of neuronal cells depends on accurate regulation of intracellular ion concentration. For example, SLC9A1 knockout mice exhibit an obvious neuronal phenotype, displaying ataxia and recurrent seizures, and null mice show increased neuronal excitability. ${ }^{31}$ One could predict that SLC9A9 plays a role in neuronal cell function.

Of note is a recent genome wide scan of 126 sibling pairs affected by ADHD, ${ }^{32}$ where a QTL peak (lod 1.37, P 0.0060) occurs over the marker D3S1569. This marker is located in intron 5 of the SLC9A9 gene (fig ID). Although the lod score did not exceed the QTL threshold for significance, its location within one of our candidates suggests that this gene could play a role in the development of the ADHD phenotype in the affected population.

Until further studies are performed, we therefore cannot determine if one or both of these genes are causing the behavioural and intellectual condition seen in this family. Neither can we conclude if the condition is caused by haploinsufficiency of the gene product of one or both genes, or if the abnormal gene products interfere with the function of the wild type products. It is also possible that the disruption of the genes DOCK3 and SLC9A9 mediates a positional effect on the expression levels of a neighbouring gene. Crisponi et al..$^{33}$ found that although a translocation breakpoint in an individual with blepharophimosis/ptosis/ epicanthus inversus syndrome is located within the C3orf5 gene, the FOXL2 gene $180 \mathrm{~kb}$ upstream of the breakpoint is responsible for the phenotype. Similarly, the possibility that a novel gene is created at the breakpoints by juxtaposing parts of the DOCK3 and SLC9A9 genes has not been disproved. The two breakpoints are located such that an in frame joining of the parts of the two genes is possible. It is possible to amplify a chimeric sequence between the $5^{\prime}$ segment of SLC9A9 and the $3^{\prime}$ region of DOCK3 in the available cells (lymphoblasts and fibroblasts) from affected individuals (data not shown). It is not known whether this transcript is translated or if any resultant protein would be functional. Efforts to amplify the alternative hybrid sequence have as yet proven unsuccessful, probably due to the restricted expression pattern of DOCK3. Transcripts under control of the DOCK3 promoter are likely to be expressed only in the brain or testis.

The novel genetic resource in this family has allowed the identification of at least one gene involved in this behavioural-developmental phenotype segregating with the chromosome 3 inversion. This paper describes the process utilised to define the breakpoints and the discovery and characterisation of two genes, DOCK3 and SLC9A9, interrupted by the inversion. Both genes are expressed in the brain 




$3 p$

ATCAGTAATTTTATATATTAA

TAGTCATTAAAATATATAATT
АСАТTCСАTTTGCTTATTAAA

TGTAAGGTAAACGAATAATTT

Figure 5 The sequence at the breakpoints is shown. The top panel shows the normal chromosome sequence with the $\mathrm{p}$ arm bases in grey and the $\mathrm{q}$ arm in black. The lower panel represents the inverted chromosome where $p$ and $q$ material is now abnormally juxtaposed. In the inversion process four base pairs are lost at the $p$ arm breakpoint and one at the $q$ arm. The $V$ shaped lines indicate the lost bases and their positions in the sequence.

but have not been previously associated with behavioural or developmental conditions. Our genetic analysis will enable us to design future studies to investigate to what extent the gene(s) contribute to the overall incidence of behavioural disorders such as ADHD. Better diagnostic testing based on genetic analysis and development of appropriate treatment modalities may be significant outcomes available sooner than previously predicted.

\section{ACKNOWLEDGEMENTS}

The authors wish to thank E Doherty, M Knight, and A Osborn for their expert technical assistance. The project was funded by the Murdoch Childrens Research Institute, the Apex Foundation for Research into Intellectual Disability Limited, the Rebecca L Cooper Medical Research Foundation Limited and the Collaborative Research Centre for the Discovery of Genes for Common Human Diseases. The CRC for Discovery of Genes for Common Human Diseases is established and supported by the Australian Government's Cooperative Research Centre's Program.

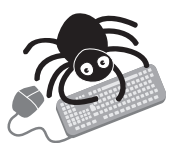

Figures 2 and 4 can be viewed on the JMG website (www.jmedgenet.com)

\section{Authors' affiliations \\ M G de Silva, K Elliott* , H-H Dahl, E Fitzpatrick, S Wilcoxt, $M$ Delatycki, R Williamson, D Efron, M Lynch, S Forrestt, Murdoch Children's Research Institute, Royal Children's Hospital, Parkville, Victoria, Australia, and the Cooperative Research Centre for Discovery of Genes for Common Human Diseases, Richmond, Victoria, Australia H-H Dahl, M Delatycki, R Williamson, S Forrest, Department of Paediatrics, University of Melbourne, Parkville, Victoria, Australia M Delatycki, Genetic Health Services Victoria, Royal Children's Hospital, Parkville, Victoria, Australia, and Department of Paediatrics, Monash University, Clayton, Victoria, Australia \\ D Efron, Centre for Community Child Health, Royal Children's Hospital, Parkville, Victoria, Australia \\ †Current Address: Australian Genome Research Facility, Walter and Eliza Hall Institute, Parkville, Victoria, Australia \\ *Current Address: International Diabetes Institute, Caulfield, Victoria, Australia}

\section{REFERENCES}

1 Martin N, Scourfield J, McGuffin P. Observer effects and heritability of childhood attention-deficit hyperactivity disorder symptoms. Br J Psychiatry 2002;180:260-5.

2 Thapar A, Holmes J, Poulton K, Harrington R. Genetic basis of attention deficit and hyperactivity. Br J Psychiatry 1999;174:105-11.
3 Efron D, Delatycki MB, de Silva MG, Langbein A, Slaghuis W, Larson A Dahl HH, Forrest SM. A novel pericentric inversion of chromosome 3 cosegregates with a developmental-behavioural phenotype. J Med Genet 2003;40:E15.

4 Webber LM, Garson OM. Fluorodeoxyuridine synchronization of bone marrow cultures. Cancer Genet Cytogenet 1983;26:123-32.

5 ISCN. An international system for human cytogenetic nomenclature. Basel: Karger, 1995.

6 Heng HHQ, Tsui L-C. In: Choo KHA, ed. FISH detection on DAPI-banded chromosomes. In situ hybridisation protocols. Ottowa: Humana Press, 1994:35-49.

7 Feinberg AP, Vogelstein B. A technique for radiolabelling DNA restriction endonuclease fragments to high specific activity. Analyt Biochem 1983;132:6-13.

8 Riehtman H, Birren B, Gnirke A. Preparation, manipulation, and mapping of HMW DNA. New York: Cold Spring Harbor Laboratory Press, 1997.

9 Spalletta G, Pasini A, Pau F, Guido G, Menghini L, Caltagirone C. Prefrontal blood flow dysregulation in drug naive ADHD children without structural abnormalities. J Neural Transm 2001;108:1203-16.

10 Barbelivien A, Ruotsalainen S, Sirvio J. Metabolic alterations in the prefrontal and cingulate cortices are related to behavioral deficits in a rodent model of attention-deficit hyperactivity disorder. Cereb Cortex 2001;11:1056-63.

11 Cardinal RN, Pennicott DR, Sugathapala CL, Robbins TW, Everitt BJ. Impulsive choice induced in rats by lesions of the nucleus accumbens core. Science 2001;292:2499-501.

12 Fukui $Y$, Hashimoto O, Sanui T, Oono T, Koga H, Abe M, Inayoshi A, Noda M, Oike M, Shirai T, Sasazuki T. Haematopoietic cell-specific CDM family protein DOCK2 is essential for lymphocyte migration. Nature 2001;412:826-31

13 Lehmann R. Cell migration in invertebrates: clues from border and distal tip cells. Curr Opin Genet Dev 2001;11:457-63.

14 Reddien PW, Horvitz HR. CED-2/Crkll and CED-10/Rac control phagocytosis and cell migration in Caenorhabditis elegans. Nat Cell Biol 2000;2(3):131-6.

15 Wu YC, Horvitz HR. C. elegans phagocytosis and cell-migration protein CED5 is similar to human DOCK180. Nature 1998;392:501-4.

16 Nolan KM, Barrett K, Lu Y, Hu KQ, Vincent S, Settleman J. Myoblast city, the Drosophila homolog of DOCK180/CED-5, is required in a Rac signaling pathway utilized for multiple developmental processes. Genes Dev 1998; 12:3337-42.

17 Erickson MR, Galletta BJ, Abmayr SM. Drosophila myoblast city encodes a conserved protein that is essential for myoblast fusion, dorsal closure, and cytoskeletal organization. J Cell Biol 1997:138:589-603.

18 Kiyokawa E, Hashimoto Y, Kobayashi S, Sugimura H, Kurata T, Matsuda M. Activation of Racl by a Crk SH3-binding protein, DOCK180. Genes Dev 1998; 12:3331-6.

19 Mackay DJ, Hall A. Rho GTPases. J Biol Chem 1998:273:20685-8.

20 Nishihara H, Kobayashi S, Hashimoto Y, Ohba F, Mochizuki N, Kurata T, Nagashima K, Matsuda M. Non-adherent cell-specific expression of DOCK2, a member of the human CDM-family proteins. Biochim Biophys Acta 1999:1452:179-87.

21 Hasegawa H, Kiyokawa E, Tanaka S, Nagashima K, Gotoh N, Shibuya M, Kurata T, Matsuda M. DOCK180, a major CRK-binding protein, alters cell morphology upon translocation to the cell membrane. Mol Cell Biol 1996:16:1770-6.

22 Kashiwa A, Yoshida H, Lee S, Paladino T, Liu Y, Chen Q, Dargusch R, Schubert D, Kimura $H$. Isolation and characterization of novel presenilin binding protein. J Neurochem 2000;75:109-16.

23 Chen Q Yoshida H, Schubert D, Maher P, Mallory M, Masliah E. Presenilin binding protein is associated with neurofibrillary alterations in Alzheimer's disease and stimulates tau phosphorylation. Am J Pathol 2001;159:1597-602

24 Wolfe MS, Haass $C$. The role of presenilins in gamma-secretase activity. J Biol Chem 2001;276:5413-6. 
25 Wakabayashi S, Shigekawa M, Pouyssegur J. Molecular physiology of vertebrate $\mathrm{Na}+/ \mathrm{H}+$ exchangers. Physiol Rev 1997;77:51-74.

26 Orlowski J, Grinstein S. Na+/H+ exchangers of mammalian cells. J Biol Chem 1997;272:22373-6.

27 Yun CH, Tse CM, Nath SK, Levine SA, Brant SR, Donowitz M. Mammalian $\mathrm{Na}+/ \mathrm{H}+$ exchanger gene family: structure and function studies. Am J Physiol 1995;269:G1-11.

28 Numata M, Orlowski J. Molecular cloning and characterization of a novel $(\mathrm{Na}+, \mathrm{K}+) / \mathrm{H}+$ exchanger localized to the trans-Golgi network. J Biol Chem 2001;276:17387-94

29 Numata M, Petrecca K, Lake N, Orlowski J. Identification of a mitochondrial $\mathrm{Na}+/ \mathrm{H}+$ exchanger. J'Biol Chem 1998;273:6951-9.

30 Bear MF, Connors BW, Paradiso MA. Neuroscience: exploring the brain, 2nd ed. Baltimore: Lippincott Williams \& Wilkins, 2001.
31 Gu XQ, Yao H, Haddad GG. Increased neuronal excitability and seizures in the $\mathrm{Na}(+) / \mathrm{H}(+)$ exchanger null mutant mouse. Am J Physiol Cell Physiol 2001;281:C496-503.

32 Fisher SE, Francks C, McCracken JT, McGough JJ, Marlow AJ, MacPhie IL, Newbury DF, Crawford LR, Palmer CG, Woodward JA, Del'Homme M, Cantwell DP, Nelson SF, Monaco AP, Smalley SL. A genomewide scan for loci involved in attention-deficit/hyperactivity disorder. Am J Hum Genet 2002;70: $1183-96$.

33 Crisponi L, Deiana $M$, Loi A, Chiappe F, Uda M, Amati P, Bisceglia L, Zelante L, Nagaraja R, Porcu S, Ristaldi MS, Marzella R, Rocchi M, Nicolino M, Lienhardt-Roussie A, Nivelon A, Verloes A, Schlessinger D, Gasparini P, Bonneau D, Cao A, Pilia G. The putative forkhead transcription factor FOXL2 is mutated in blepharophimosis/ptosis/epicanthus inversus syndrome. Nat Genet 2001;27:159-66.

\section{$\mathrm{ECHO}$}

\section{Age at onset and female sex typify primary congenital glaucoma with CYP1B 1 mutation}

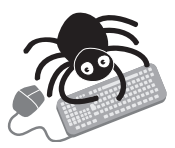

Please visit the Journal of Medical Genetics website [www. jmedgenet. com] for a link to the full text of this article. nderstanding how primary congenital glaucoma (PCG) occurs may be a little closer now that the phenotype of the P4501Bl (CYPIBI) gene mutation in Japanese infants has been determined.

A case series of 32 infants, all but one with sporadic PCG, was tested for CYPIBI gene mutations: 11 had mutations in both alleles, the others had none. The defining features of those with the mutation were early onset of the condition ( $1.7 \vee 3.1$ months) and lower male:female ratio (6:5 $v 19: 2)$. Typical signs and symptoms were present regardless of mutation status; most infants had opacity of the cornea and many had ruptures in Descemet's membrane. Nearly all those with the mutation and $87 \%$ of those without had disease in both eyes.

Four cases with the mutation were special. One had a unique phenotypic trait which may point to a new classification of PCG in infants based on whether the CYPIBI mutation is present or not. Another was a compound heterozygote with C313OT mutation, whose late presentation suggests that this mutation affects P4501Bl expression. Compound heterozygotic identical twins with Ala330Phe and Val364Met mutations showed discordance in visual acuity, maybe indicating an environmental influence.

DNA from leucocytes was used to screen for CYPIBI mutations by PCR amplification and single strand conformational analysis followed by DNA sequencing. Clinical features at onset of the condition were compared from the hospital notes in each case.

PCG is rare and occurs at very different frequencies in different ethnic populations. In Japan most cases are sporadic.

A British Journal of Ophthalmology 2003;87:302-304. 